\title{
Single-Chip Two Antennas for MM-Wave Self- Powering and Implantable Biomedical Devices
}

Dalia Elsheakh ( $\square$ daliaelsheakh@gmail.com )

Faculty of Engineering \&amp; Technology College https://orcid.org/0000-0002-6168-7681

Somaya I Kayed

Abour High Institute

Heba Shawkey

Electronics Research Institute

\section{Research Article}

Keywords: On chip antenna, multi-band meander-line (MBML), wideband dipole antenna (WBDA), implantable antenna, radio frequency energy harvesting, UMC $180 \mu \mathrm{m}$ CMOS

Posted Date: April 15th, 2021

DOI: https://doi.org/10.21203/rs.3.rs-332417/v1

License: (c) (i) This work is licensed under a Creative Commons Attribution 4.0 International License. Read Full License 


\section{Abstract}

Implantable biomedical applications arise the need for multi-band sensors with a wideband frequency channel for RF energy harvesting operation. Using a separate antenna for energy harvesting can simplify device circuit complexity and reduces operation frequency bands interference. This paper demonstrates the design of single chip with two separate integrated antennas for implantable biomedical applications. The two antennas have different structures with orthogonal polarization to achieve low mutual coupling and negligible interaction between them. The first antenna is a multi-band meander line (MBML) designed for multiple channels data communication, with quad operating bands in the MM-wave range from $22-64 \mathrm{GHz}$ with area $1150 \times 200 \mu \mathrm{m}^{2}$. The second antenna is a wideband dipole antenna (WBDA) for RF energy harvesting, operates in the frequency range extend from $28 \mathrm{GHz}$ to $36 \mathrm{GHz}$ with area $1300 \times 250 \mu \mathrm{m}^{2}$. The proposed antennas are designed by using high frequency structure simulator (HFSS) and fabricated by using UMC180nm CMOS technology with total area $0.55 \mathrm{~mm}^{2}$. The MBML frequency bands operating bandwidths can reach $2 \mathrm{GHz}$ at impedance bandwidth $\leq-10 \mathrm{~dB}$. While, the WBDA antenna has gain $-2 \mathrm{~dB}$ over the operating band extend from $28 \mathrm{GHz}$ up to $36 \mathrm{GHz}$. The antenna performance is simulated separately and using the human-body phantom model that describes layers of fats inside body, and shows their compatibility for in body operation. Die measurements is performed using on wafer-probing RF PICOBROBES and shows the matching between simulation and measurement values.

\section{Introduction}

Currently, promising implantable systems have been proposed for healthcare monitoring and remote sensing to improve the lifestyle of the patients. UWB frequency bands are applied for implantable devices as it enables high data rate and multiple frequency channels for multimode operation [1-5]. Recently, MMW range is described as a complementary imaging technique instead of exposure of patient to radiations as magnetic resonance, X-Ray or Ultrasound [6-8]. The antennas depend on $5 \mathrm{G}$ technology to meet the capacity, latency and the bandwidth requirements to support the request of the growing number of wireless communication users [9-10]. Besides, antenna and associated electronics could be designed to support multiple frequency channels for data communications of a group of implantable sensors simultaneously, with the need for a wideband frequency channel for RF energy harvesting to obtain a suitable power level for device operation [11-14]. Figure 1 shows the energy/power required for device operation can be obtained using energy harvester/wireless powering transfer from external source to be applied to the implantable devices in different locations in-body. Different types of on-chip implantable antennas are described in the sub GHz range and MMW range [15-20].

Simultaneous data communication mode and RF wireless powering mode using same antenna and matching network [21-22] where the antenna toggles between the 2 communication modes, the data mode and power mode, but this needs special control technique to fulfil continuous switching between both modes. To reduce circuit complexity, the modes of operation can be split up by using two separate antennas, one is used for data communication (for multiple sensors) while the other operates for RF 
energy harvesting. In this paper, two separate integrated antennas on the same chip are proposed to be used for self-powering implantable biomedical devices. The antennas are designed for data communication and energy harvesting simultaneously, with two different structures are designed, a multiband meander line antenna (MBML) and a wide-band dipole antenna (WBDA), with no radiation coupling occurs. The MBML resonates at the $22,36,48,60 \mathrm{GHz}$, such that it is suitable for multiple sensing applications, while the WBDA operates from $28 \mathrm{GHz}-36 \mathrm{GHz}$ to perform the wideband required for energy harvesting. The 3D configuration of the proposed antennas shown in Fig.2, is fabricated using UMC $0.18 \mu \mathrm{m}$ CMOS technology with 6-Metal layers. As implantable devices are affected by the permittivity of human tissues which causes signal losses, antenna design should consider the humanbody effect during antenna design as wireless transfer between the on-body device and the external electronic circuits. For human activity monitoring, the implant is set to be below the human scalp or embedded in the muscle [23].

In this paper, the chip is assumed for implantation in the fat layer of the human body. Phantom model is used to investigate the antenna signal transmission in the human body layers even in the presence of perturbations such as embedded muscle layers and blood vessels. The paper sections are organized as follows, Section 2 shows detailed explanation of the proposed antennas configuration. Section the simulation and measurement performance of both antennas. In section 4, the proposed antenna simulation using human-phantom is performed to investigate antenna compatibility with implantable applications. Finally, conclusions of the paper are shown in section 5 .

\section{Antenna Configuration And Design}

Different shapes of on-chip integrated antennas are shown, as dipole [17], [24], [25], loop [18-20], zigzag [26], [27], and bowtie antennas [28], [29]. This is due to their circuits have differential input / output. The design of the two balanced antennas are utilized to obtain the benefits of the on-chip ground plane used to improve antenna radiation efficiency. Two different shapes of antennas are used to seeking different wireless applications, one for the data communication antenna and the second for wireless powering antenna integrated on the same chip with separate connecting PADS as shown in Fig. 3. The chip is fabricated by using UMC $180 \mathrm{~nm}$ CMOS process with silicon substrate and six metal layers. In this section, design and simulation for each antenna is demonstrated.

\section{2. a. Data Communication Antenna}

It is a multi-band meander line (MBML) implemented at 2 stacked layers to increase antenna total lengthlocated at metal layers $\mathrm{M}_{6}$ and $\mathrm{M}_{4}$ as shown in Fig.3. A layer of metal $\mathrm{M} 1$ is set as a ground plane to enlarge bandwidth with area of $1525 \mu \mathrm{m} \times 250 \mu \mathrm{m}$ with 4 connections to the 4 ground PADS. Each meander layer - whether at $M_{4}$ and $M_{6}$ - has a finger line width $15 \mu \mathrm{m}$, length $1150 \mu \mathrm{m}$ and line spacing $20 \mu \mathrm{m}$ between each two fingers. The meander structure at $M_{6}$ layer has five fingers while the meander structure at $\mathrm{M}_{4}$ layer has only four fingers as shown in Fig. 2. The two layers have the same alignment but shifted $17.5 \mu \mathrm{m}$, to increase number of resonance frequency bands. Five PADS are used with area 
$80 \mu \mathrm{m} \times 60 \mu \mathrm{m}$ for each and separated by $150 \mu \mathrm{m}$. One of the PADs is connected tom the upper meander layer M6 to be used as signal PAD and the others are used as ground PADs. The MBML has a 50ohm line connection with signal PAD. The two meander layers are connected through via 1.

\section{2. b. RF Energy Harvester Antenna}

Fig.3 shows the structure of the wideband dipole antenna used for RF energy harvesting. It is composed of three layers, a dipole layer, a patch layer, and a ground plane. The dipole consisting of a half wavelength radiating dipole implemented at the upper metal layer $M_{6}$ with total area $1300 \mu \mathrm{m} \times 250 \mu \mathrm{m}$. The patch layer is carried out in the intermediate metal layer $M_{4}$ with area $1100 \mu \mathrm{m} \times 50 \mu \mathrm{m}$. This middle patch layer acts as a parasitic element to broaden the antenna bandwidth. A ground layer is set at the M1 layer with area $1300 \mu \mathrm{m} \times 250 \mu \mathrm{m}$. The patch layer is stacked to the dipole by $\mathrm{VIA}_{1}$. The signal and ground PADs (with area $80 \mu \mathrm{m} \times 60 \mu \mathrm{m}$ ) are separated by $150 \mu \mathrm{m}$. The ground M1 layer is connected to the Ground PAD by $\mathrm{VIA}_{2}$. The proposed dipole antenna with patch layer is set to reduce the resonant frequency and increase the antenna bandwidth. The corresponding reflection coefficient response for both antennas is shown in Fig. $4(\mathrm{a})$, where $\left|S_{22}\right|$ (as dashed blue line) represents the MBML response while $\left|S_{11}\right|$ (as black line) represents the WBDA. The green line explains the neglected coupling between both antennas. Current distribution at different tuning frequencies on both antennas' surfaces are shown in Fig. 5 . The highest magnitude of current represents the corresponding element of radiation.

\section{Antenna Measurements Results}

The measured antenna S-parameters are carried out by using cascade probe station on top with Anritsu Vector Network as shown in Fig. 6 . The measured reflection coefficient is achieved by using on-wafer probing. The measurements setup shown in Fig.6, composed of one GSG $70 \mathrm{GHz}$ PicoProbe-RF probe (pitch: $150 \mu \mathrm{m}$ ) and Anritsu Vector Network analyzer up to $70 \mathrm{GHz}$. The UMC180nm setup die (miniasic $1.525 \mathrm{~mm} \times 1.525 \mathrm{~mm}$ ) is fabricated and fixed at PM5 KarlSuss manual probe-station. The fabricated photo of the proposed antennas are shown in Fig. 6 with four ground PADS connected to the ground metal layer $M_{1}$, the extra PADS have no effect on antenna performance but are added due to measurements concerns. To ensure the reliability and accuracy of measurements; the proper fixture is applied. The die is fixed on the probe-station holder using vacuum pump while the GSG probe and the positioner are held by a manipulator that has magnetic fixture to ensure accurate contact between the die and the GSG probe. The other measurement problems that could be cause uncertainty of measurements [30] which is avoided by using a calibration substrate at the beginning of the measurements to ensure accurate calibration for the complete setup (network analyzer, cabling and probe) whenever it produces a reading different than the standard. Besides, before each measurement experiment the VNA was calibrated using (the open short, through calibration kit).

Fig. 7(a) shows the comparison between the simulated and measured reflection coefficients $\left|S_{11}\right|$ of the double meander antenna. However, the $\left|S_{11}\right|$ of the different dipole length is shown in Figure $7(b)$. The comparison between simulated and measured results showed that there are a good agreement between 
the lower and the upper of the operating frequencies' antenna bands. There are some ripples in the measured results and there are about $-3 \mathrm{~dB}$ shift in the measured reflection coefficient results. These errors could be attributed to metal holder, which are not considered and many factors as the thickness of the layer, metal holder was not taken into account. In addition, uncertainty in the dielectric material properties are specified up to $15 \mathrm{GHz}$ while the simulated dielectric material properties of the layer were identified up to $70 \mathrm{GHz}$ so that the permittivity of the dielectric layer was somewhat higher than the permittivity that is identified at lower frequency. As well as the influence of larger wafer with the chuck and the uncertainty in the dielectric material properties. In the simulations, these values have been used for the characterization of the structure at $70 \mathrm{GHz}$. Table 1 shows the radiation pattern of the MBMA at different resonant frequencies. While table 2 shows the simulated polar radiation pattern for the WBDA antenna at three resonant frequencies $28 \mathrm{GHz}, 32 \mathrm{GHz}$ and $32 \mathrm{GHz}$, respectively.

Table 1 . The 2D polar radiation pattern - without human-body, - - - with human-body at different resonant frequencies.

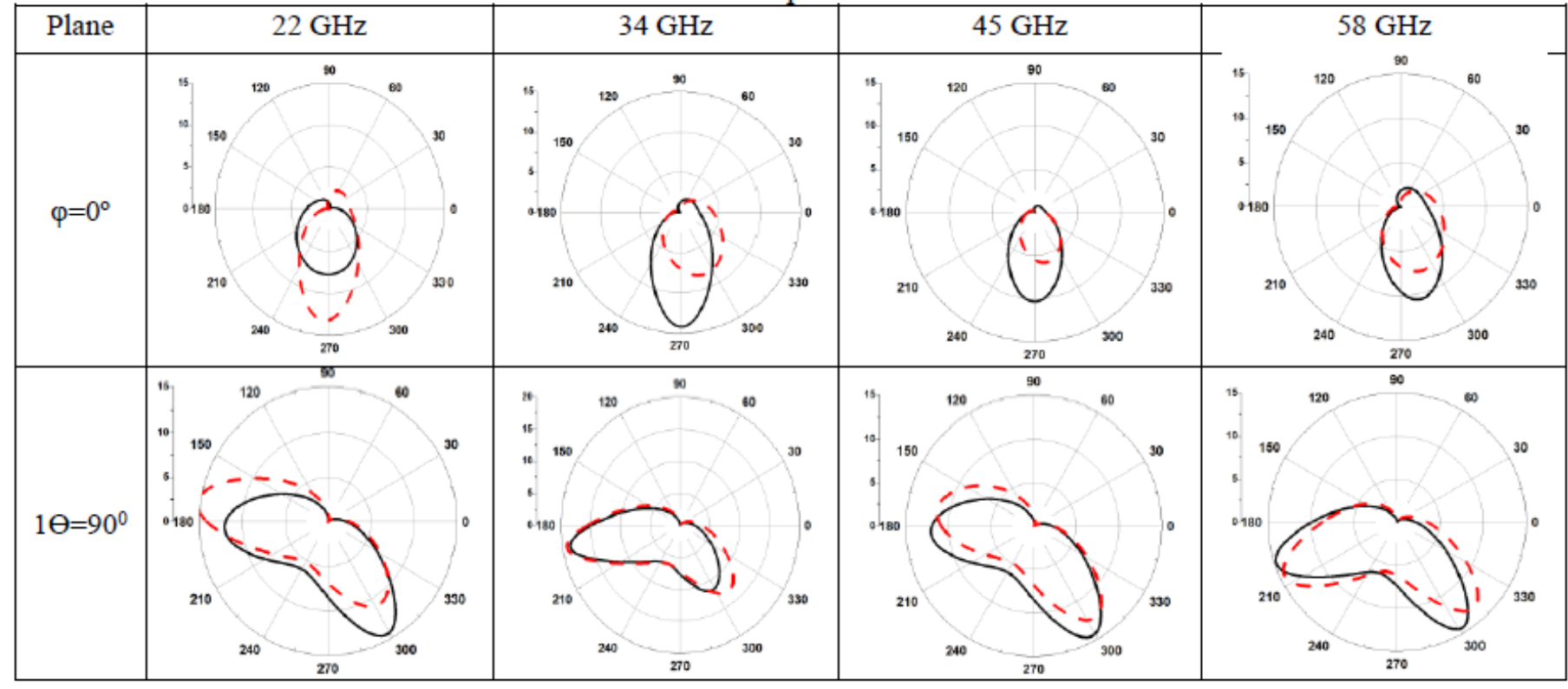

Table 2 THE 2D polar radiation pattern - $\Phi=0^{\circ},-\cdot-\Phi=90^{\circ}$, and $-\cdot \cdot-\theta=90^{\circ}$ at different resonant frequencies.

\begin{tabular}{|c|c|c|}
\hline $28 \mathrm{GHz}$ \\
\hline
\end{tabular}

\section{Human-body Phantom Modeling}


To validate the performance of the proposed antennas for implantable applications, phantom model is used to simulate the implanted antenna and evaluate its performance to be used in-body environment. Fig. 8 shows the homogeneous multilayered model with a dimension of $80 \times 40 \times 63 \mathrm{~mm}^{3}$ used to model human tissue [31]. The values of electrical properties are tuned around $40 \mathrm{GHz}$, the implanted depth in skin layer is $2 \mathrm{~mm}$.

The results showed that when the human body effect is included in the simulation, the antenna impedance matching is more significant for the chip implanted inside the human body. The resonant frequencies are reduced and the operating bandwidths are broaden. Moreover, the phase of the reflection coefficient was slightly changed when the chip is placed outside a human body, and it was abruptly changed when the antenna was implanted in the human body. The changed results of the antenna performance are due to the conductivity of the human body, which adds extra load on the antenna surface and changes in the electrical properties of the substrate. However, when the chip is implanted in the human body, it became more dispersive and the operating bandwidths at $-10 \mathrm{~dB}(V S W R \leq 2)$ were extended from $20 \mathrm{GHz}$ to $45 \mathrm{GHz}$ and from $57 \mathrm{GHz}$ up to $65 \mathrm{GHz}$. However, in both simulation scenarios, the antenna bandwidth still operated in the selected bands of operations.

\begin{tabular}{|c|c|c|c|c|c|c|c|}
\hline \multicolumn{8}{|c|}{ Table 3: Comparison of the proposed antenna with other on-chip antennas } \\
\hline Ref & [15] & {$[16]$} & [17] & [18] & [19] & {$[20]$} & This work \\
\hline Type & Dipole & & Spiral Slot & Loop & Loop & Loop & Meander/Dipole \\
\hline Freq & $915 \mathrm{MHz}$ & $24 / 60 \mathrm{GHz}$ & $0.9 \mathrm{Ghz}$ & $60 \mathrm{Ghz}$ & $\begin{array}{c}434 \\
\mathrm{MHz}\end{array}$ & $67 \mathrm{GHz}$ & $\begin{array}{c}22 / 34 / \\
44 / 58 \mathrm{GHz} . \\
26-34 \mathrm{GHz}\end{array}$ \\
\hline Gain & $-56 d B$ & $-9 /-1 d B$ & $-90 \mathrm{~dB}$ & $-3.2 \mathrm{dBi}$ & $\begin{array}{c}16.45 \\
\mathrm{~dB}\end{array}$ & $8 \mathrm{dBi}$ & $-20 /-15 /-10 /-1 \mathrm{dBi}$ \\
\hline BW & $26 \mathrm{MHz}$ & 180/700MHZ & $53 \%$ & $5.5 \mathrm{GHz}$ & -- & $4 \mathrm{GHz}$ & $5 / 6 / 4 / 8 \mathrm{GHz}$ \\
\hline Area & $2.52 \mathrm{~mm}^{2}$ & $0.794 \mathrm{~mm}^{2}$ & $0.385 \mathrm{~mm}^{2}$ & $2.25 \mathrm{~mm}^{2}$ & $\begin{array}{r}2.56 \\
\mathrm{~mm}^{2}\end{array}$ & $0.875 \mathrm{~mm}^{2}$ & $0.55 \mathrm{~mm}^{2}$ \\
\hline Tech. & $\begin{array}{c}0.13 \mu \mathrm{m} \\
\mathrm{CMOS}\end{array}$ & $\begin{array}{l}0.13 \mu \mathrm{m} \\
\mathrm{CMOS}\end{array}$ & $\begin{array}{c}0.18 \mu \mathrm{m} \\
\mathrm{CMOS}\end{array}$ & $\begin{array}{c}0.18 \mu \mathrm{m} \\
\mathrm{CMOS}\end{array}$ & $\begin{array}{c}0.18 \mu \mathrm{m} \\
\mathrm{CMOS}\end{array}$ & $\begin{array}{l}0.18-\mu \mathrm{m} \\
\text { CMOS }\end{array}$ & $\begin{array}{c}0.18-\mu \mathrm{m} \\
\mathrm{CMOS}\end{array}$ \\
\hline
\end{tabular}

\section{Conclusion}

This paper described two antennas integrated on the same- chip for implantable biomedical applications. Two separate antennas are designed with orthogonal polarization to ensure neglected mutual coupling between them. The first antenna (MBML) is used for data communication with multiple resonance frequencies at $22 \mathrm{GHz}, 34 \mathrm{GHz}, 44 \mathrm{GHz}$ and $62 \mathrm{GHz}$. The other antenna (WBDA) has a wideband from $28 \mathrm{GHz}$ up to $36 \mathrm{GHz}$ and used for RF Energy Harvesting. The antennas are fabricated using UMC $180 \mathrm{~nm}$ CMOS technology with total area $0.55 \mathrm{~mm}^{2}$. Measurements for both antennas - gain and bandwidth - are matched with design and simulation results. The proposed antennas are simulated using phantom model to check their compatibility for implantable devices

\section{References}


[1] D. Elsheakh, H. Shawkey and S.Saleh, "A $9-10.6 \mathrm{GHz}$ microstrip antenna-UWB low noise with differential noise canceling technique for loT applications," International Journal of Communications, Network and System Sciences, vol.12, pp.189, 2019.

[2] R. Elyassi and G. Moradi, "Flexible and moon-shaped slot UWB implantable antenna design for head implants," International Journal of Microwave and Wireless Technologies, vol. 9, pp.1559-1567, 2017.

[3] A. Priya, S. K. Mohideen, and P. Thirumaraiselvanm “Propagation losses of UWB antenna for On-body to in-body Signal Propagation," Progress In Electromagnetics Research M, vol. 73, pp.101-109, 2018.

[4] H.Shawkey and S.Saleh, "Low-power fully monolithic MICS band receiver for 402-405 MHz implantable devices," International Journal of Electronics Vol.107, 2020 Issue 1 pp.28-45.

[5] H. Shawkey and D. Elsheakh, "Multiband dual-meander line antenna for body-centric networks biomedical applications by using UMC 180 nm," Electronics 2020, vol. 9, 1350.

[6] T. Wu, T. S. Rappaport, C. M. Collins, "The human body and millimeter-wave wireless Communication Systems: interactions and implications," IEEE International Conference on Communications (ICC) 2015.

[7] S. Di Meo, et al., "On the feasibility of breast cancer imaging systems at millimeter-waves frequencies," IEEE Trans. Microw. Theory Techn., Vol. 65, no. 5, pp. 1795-1806, May 2017.

[8] A. Martellosio, et al., "Dielectric properties characterization from 0.5 to $50 \mathrm{GHz}$ of breast cancer tissues," IEEE Trans. Microw. Theory Techn., Vol. 65, no. 3, pp. 998-1011, March 2017.

[9] M. Ali, H. Shawkey, A. Zekry, "Sawan, M. One Mbps $1 \mathrm{~nJ} / \mathrm{b}$ 3.5-4 GHz fully integrated FM-UWB transmitter for WBAN applications," IEEE Trans. Circuits Syst. I: Regul, vol. 65, pp.2005-2014, 2018.

[10] C. Liu, Y. Guo, X. Liu and S. Xiao, "An Integrated On-Chip Implantable Antenna in \$0.18-Imu \text\{m\}\$ CMOS Technology for Biomedical Applications," in IEEE Transactions on Antennas and Propagation, vol. 64, no. 3, pp. 1167-1172, March 2016.

[11] F. Gutierrez, Jr., S. Agarwal, K. Parrish, and T. S. Rappaport, "On-Chip Integrated Antenna Structures in CMOS for $60 \mathrm{GHz}$ WPAN Systems," IEEE Journal on Selected Areas in Communications, Vol. 27, No. 8, October 2009.

[12] Yuwono, Rudy \& Mujahidin, Irfan. (2019). Rectifier Using UWB Microstrip Antenna as Electromagnetic Energy Harvester for GSM, CCTV and Wi-Fi Transmitter. Journal of Communications. 1098-1103. 10.12720/jcm.14.11.1098-1103.

[13] K. ÇELIKK and E.Kurt, " A Novel Super Wideband Circular Fractal Antenna For Energy Harvesting Applications," International Symposium on Advanced Electrical and Communication Technologies (ISAECT) 2019. 
[14] M.G. Tampouratzis, D. Vouyioukas, D. Stratakis and T. Yioultsis “Use Ultra-Wideband Discone Rectenna for Broadband RF Energy Harvesting Applications," Technologies Journal (MDPI) 2020.

[15] V. Kuhn, C. Lahuec, F. Seguin, and C. Person, "A Multi-Band Stacked RF Energy Harvester with RF-toDC Efficiency Up to 84\%," IEEE Transaction on Microwave Theory and techniques, Vol. 63, No. 5, May 2015.

[16] J. Huang, J. Wu, Y. Chiou, C. Jou, "A 24/60 GHz dual-band millimeter-wave on-chip monopole antenna fabricated with a 0.13-mCMOS Technology," In Proceedings of the IEEE International Workshop on Antenna Technology, Santa Monica, CA, USA, 2-4 March 2009.

[17] A. A. Masius, Y. C. Wong “On-chip Miniaturized Antenna in CMOS Technology for Biomedical Implant," International Journal of Electronics and Communications, Vol.115 February 2020.

[18] Y, Song, Q. Xu, Y. Tian, J. Yang, Y. Wu, X. Tang, K. Kang, "An on chip frequency-reconfigurable antenna For Q-band broadband applications," IEEE Antennas Wireless Propagation Letters 2017.

[19] H. Rahmani and A. Babakhani, "A $434 \mathrm{MHz}$ Dual-Mode Power Harvesting System with an On-chip Coil in $180 \mathrm{~nm}$ CMOS SOI for mm-Sized Implants," 2018 IEEE/MTT-S International Microwave Symposium IMS, Philadelphia, PA, USA, 2018, pp. 1130-1133, doi: 10.1109/MWSYM.2018.8439642.

[20] Y. Song, Y. Wu, J. Yang and K. Kang, "The design of a high gain on-chip antenna for SoC application," Advanced Materials and Processes for RF and THz Applications (IMWS-AMP), 2015 IEEE MTT-S International Microwave Workshop Series on, Suzhou, 2015, pp. 1-3

[21] Tharindu D. Ponnimbaduge Perera, Dushantha Nalin K. Jayakody, Shree K. Sharma, Symeon Chatzinotas, Jun Li, "Simultaneous wireless information and power transfer (SWIPT): recent advances and future challenges," IEEE Communications Surveys \& Tutorials Vol.20, Issue: 1, 2018.

[22] X. Peng and J. Li , "Harvested energy maximization of SWIPT system with popularity cache scheme in dense small cell networks," Hindawi. Wireless Communications and Mobile Computing. Volume 2019

[23] J. M. Felício; C. A. Fernandes; J. R. Costa, "Wideband Implantable Antenna for Body-Area High Data Rate Impulse Radio Communication," IEEE Transactions on Antennas and Propagation Vol. 64, Issue 5, May 2016.

[24] I. El Masri, T. L. Gouguec, P. Martin, R. Allanic and C. Quendo, "Integrated dipole antennas and propagation channel on silicon in Ka band for WiNoC applications," IEEE 22nd Workshop on Signal and Power Integrity (SPI), 25 May 2018.

[25] M. Nafe, A. Syed, A. Shamim, "Gain-Enhanced On-Chip Folded Dipole Antenna Utilizing Artificial Magnetic Conductor at $94 \mathrm{GHz}$," IEEE Antennas and Wireless Propagation Letters Vol.16, September 2017. 
[26] R. S. Narde, J. Venkataraman, A. Ganguly and I. Puchades "Antenna Arrays as Millimeter-Wave Wireless Interconnects in Multi-Chip Systems," IEEE Antennas and Wireless Propagation Letters, Vol. 19, No. 11 , Nov. 2020

[27] R. S. Narde, N. Mansoor, A. Gangul, , J. Venkataraman " On-Chip Antennas for Inter-Chip Wireless Interconnections: Challenges and Opportunities," 12th European Conference on Antennas and Propagation (EuCAP) April 2018.

[28] M. S. Khan, F. A. Tahir, H. M. Cheema, "Design of bowtie-slot on-chip antenna backed with E-shaped FSS at 94 GHz," 10th European Conference on Antennas and Propagation (EuCAP) June 2016.

[29] S. Pan, L. Gilreath, P. Heydari and F. Capolino, "An On-chip W-Band Bowtie Slot Antenna in Silicon," Proceedings of the 2012 IEEE International Symposium on Antennas and Propagation, Nov.2012.

[30] M. R. Karim, X. Yang and M. F. Shafique, "On chip antenna measurement: A survey of challenges and recent trends," in IEEE Access, vol. 6, pp. 20320-20333, 2018.

[31] Y. Zhang, C. Liu, X. Liu, K. Zhang, "A miniaturized circularly polarized implantable RFID antenna for biomedical applications," International Journal of RF and Microwave Computer Aided Engineering, Wiley Periodicals, Inc. December 2019.

\section{Figures}

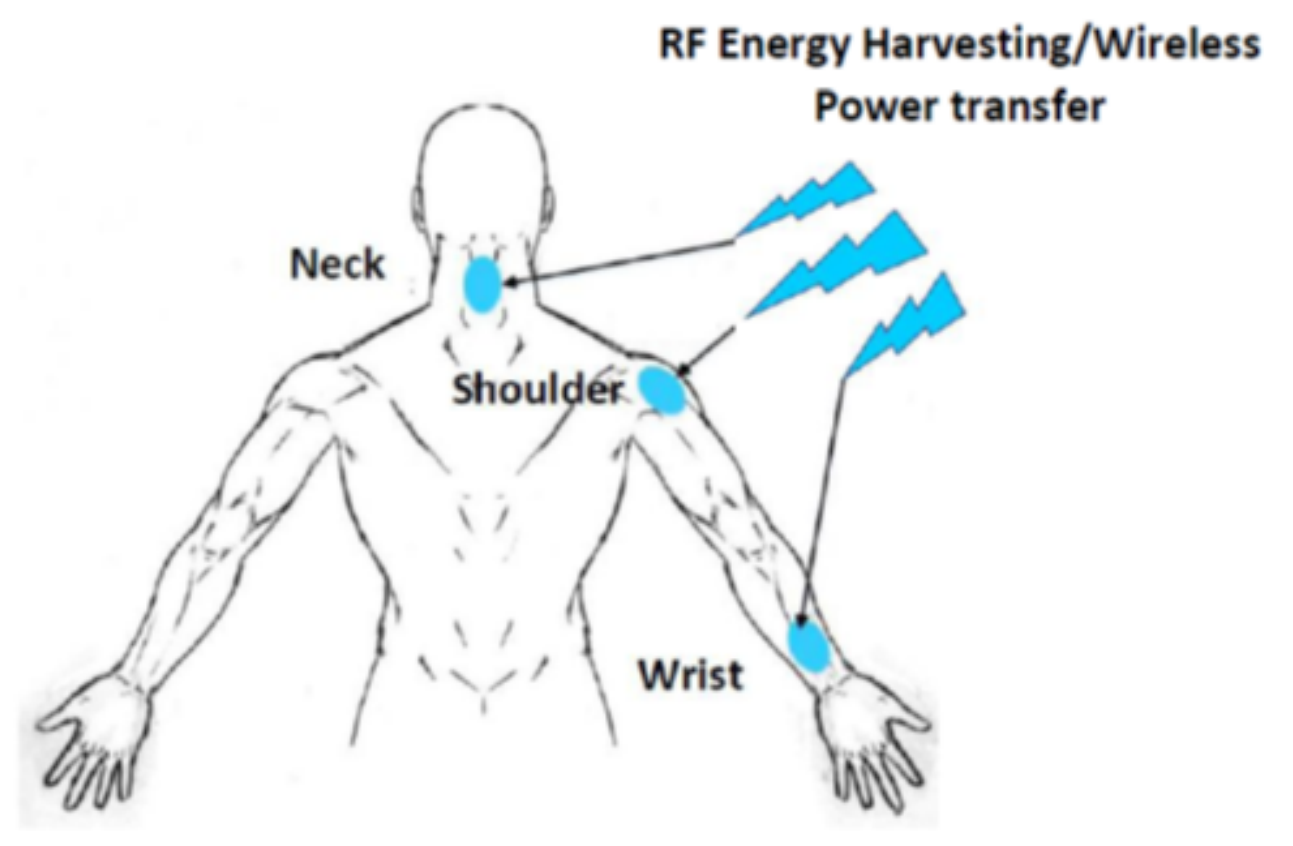

\section{Figure 1}

RF wireless powering for different implantable devices. 


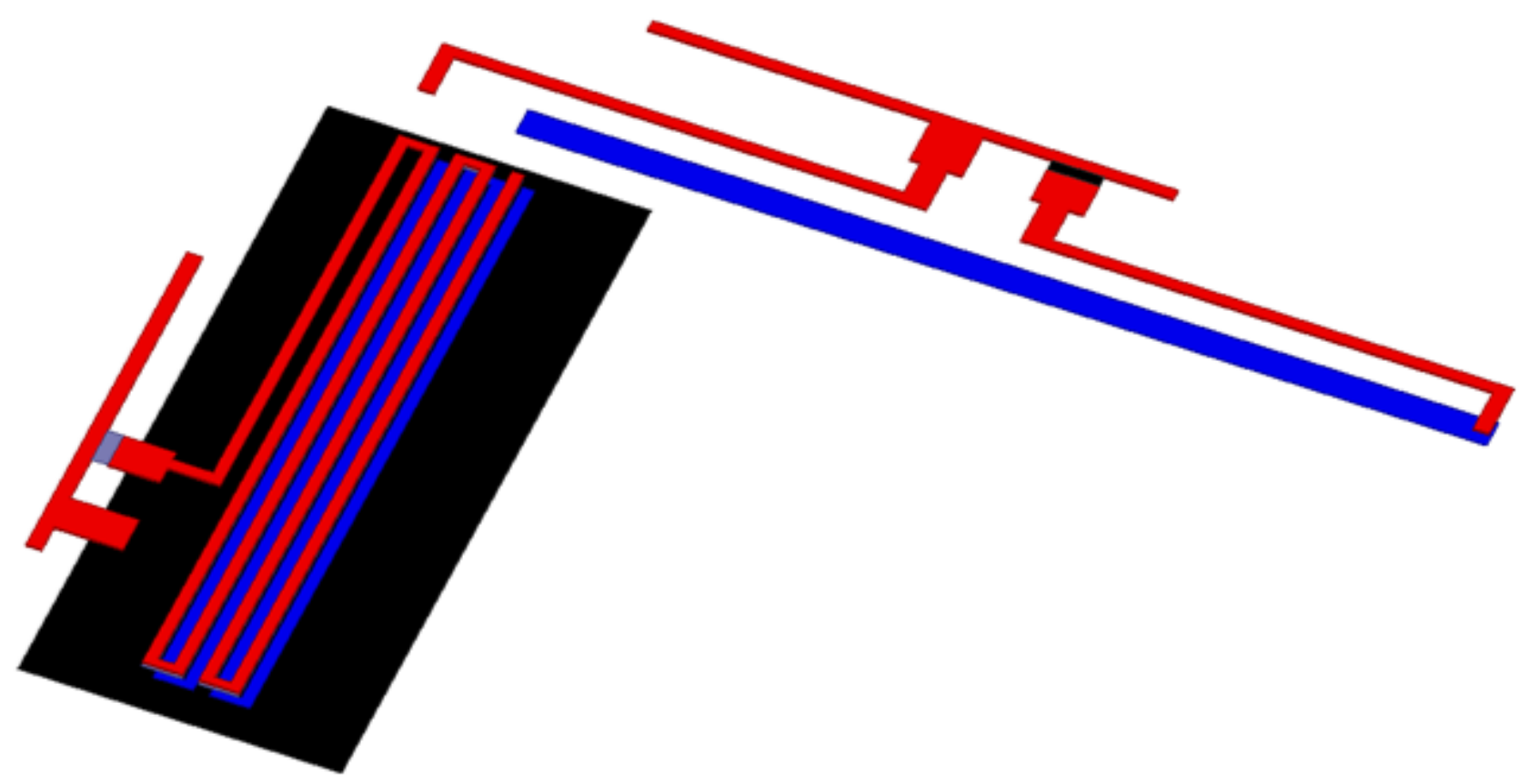

Figure 2

The 3D configuration of MIMO.

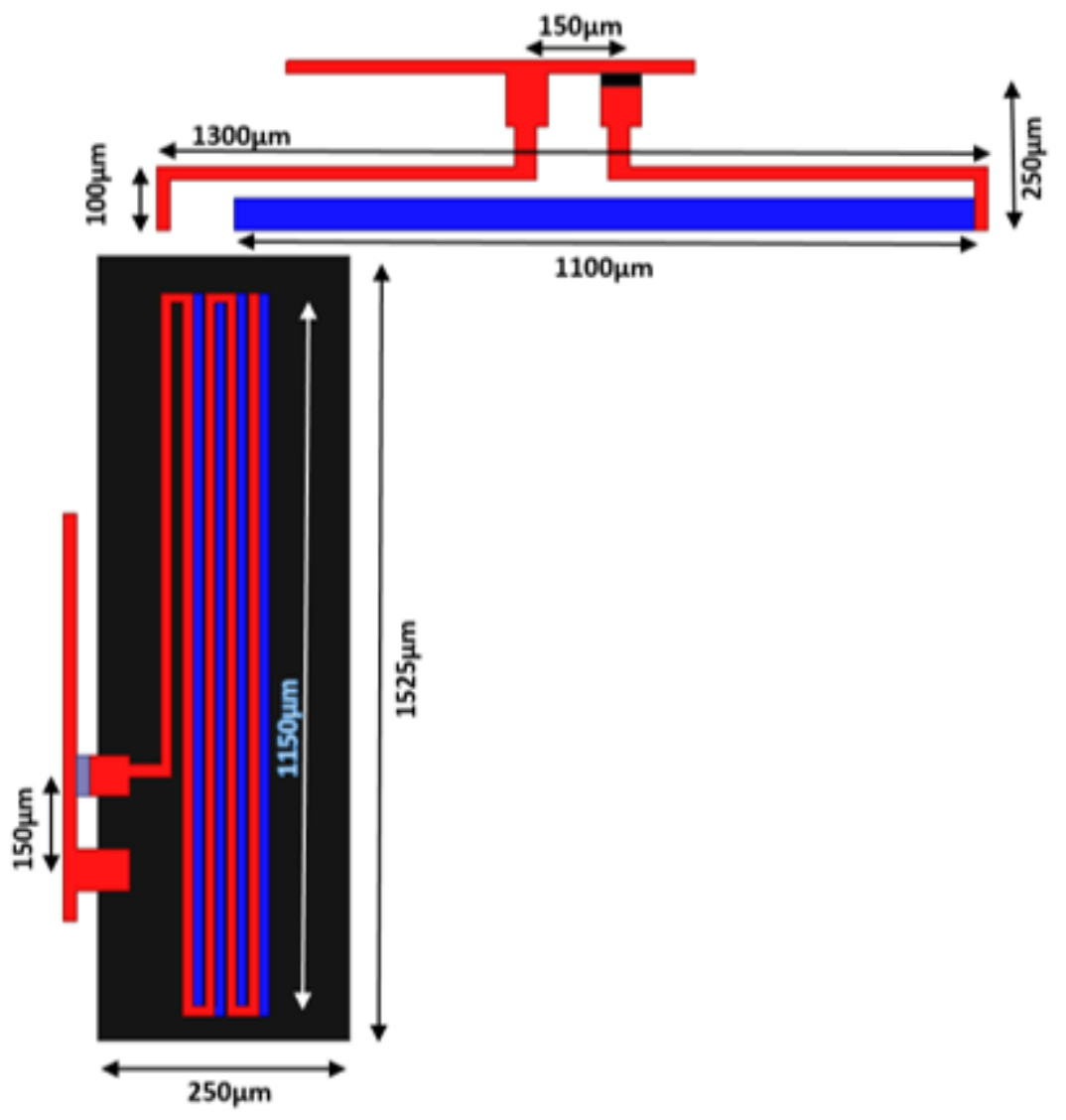

Figure 3 
Data communication of System Muti-band Meander Line and Dipole Antenna.

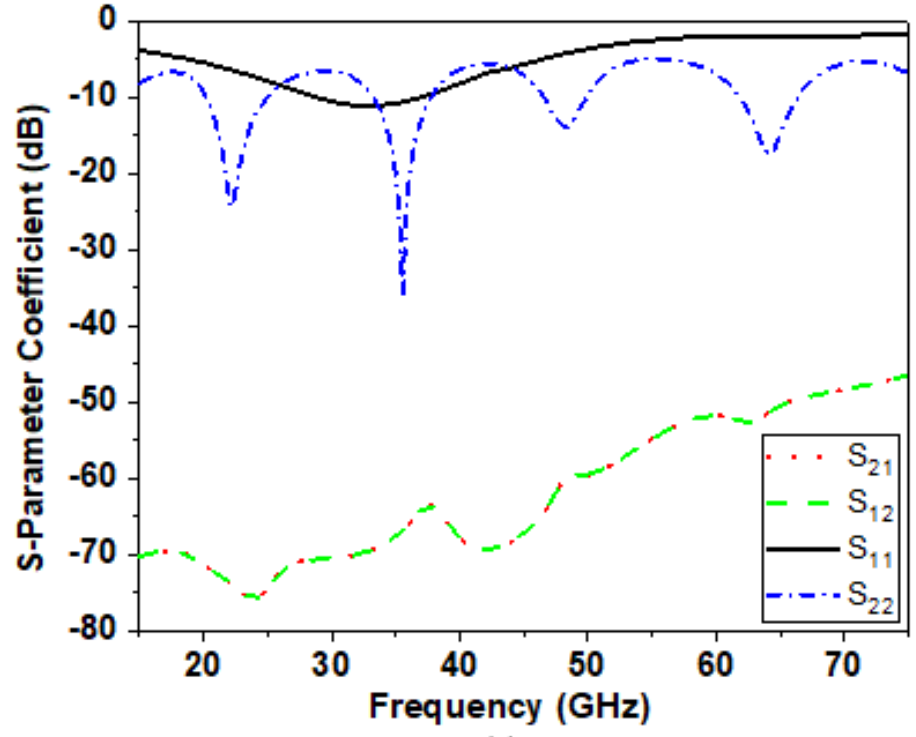

(a)

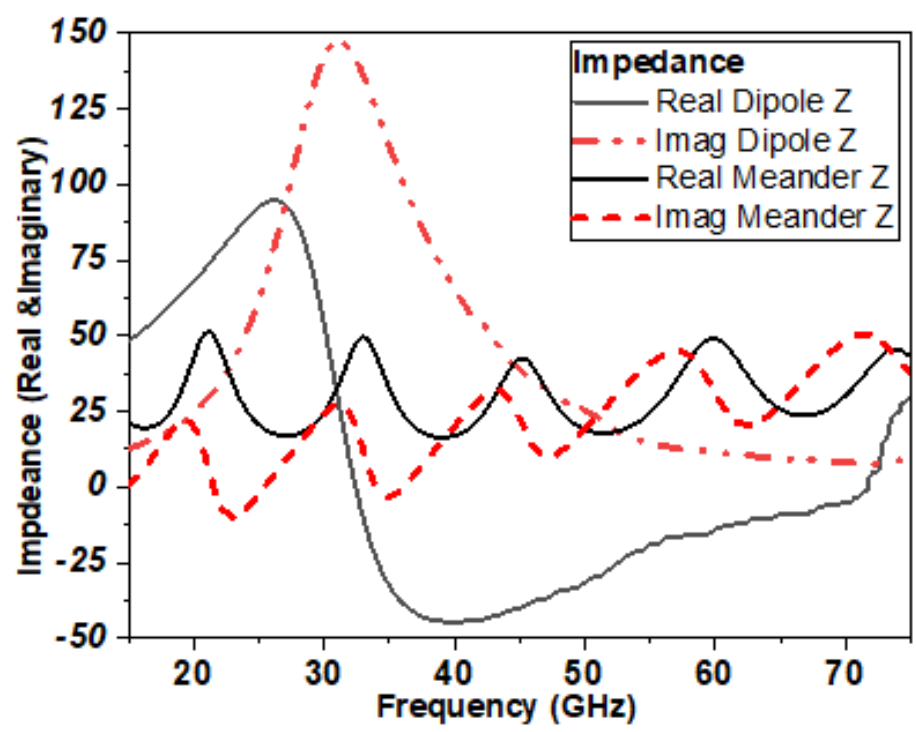

(b)

Figure 4

Scattering parameters versus frequency of the proposed antennas and (b) Input impedance real and imaginary.

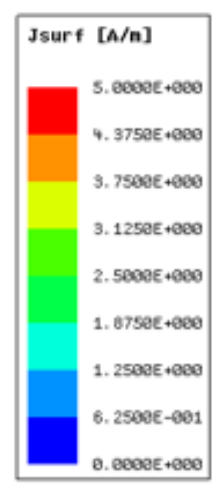

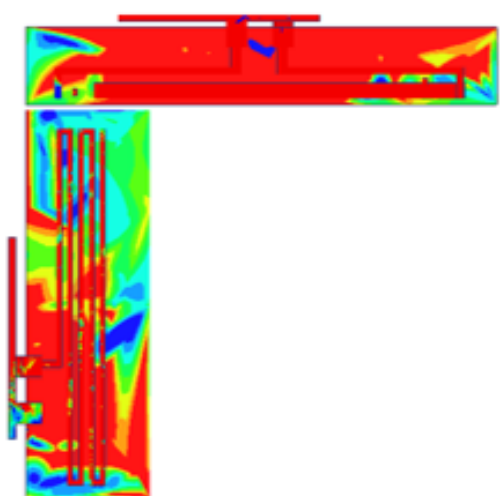

(a)

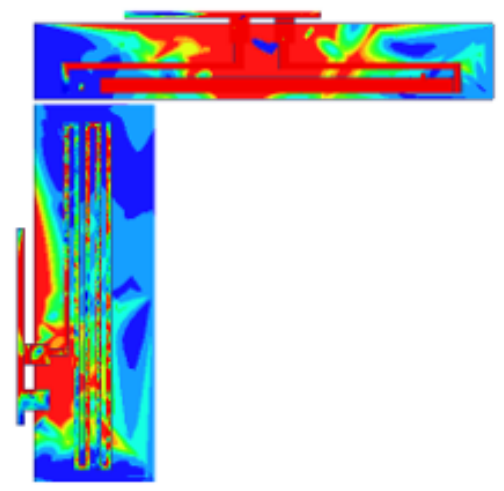

(d)

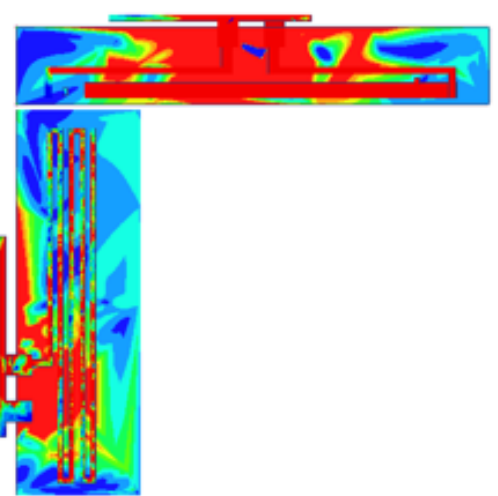

(b)

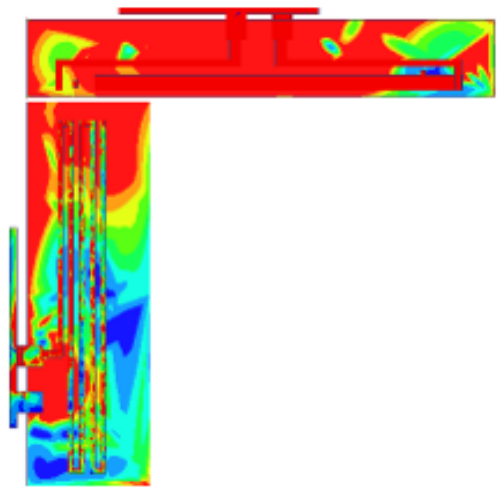

(e)

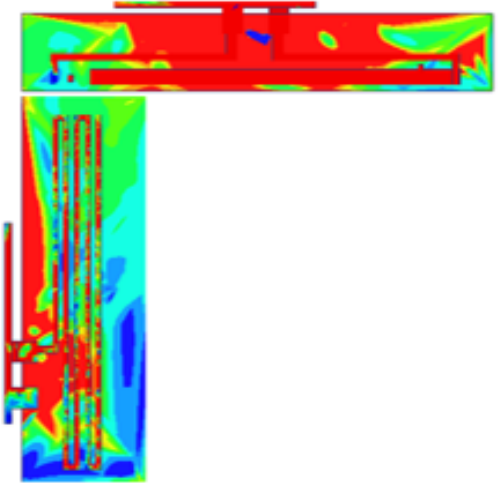

(c)

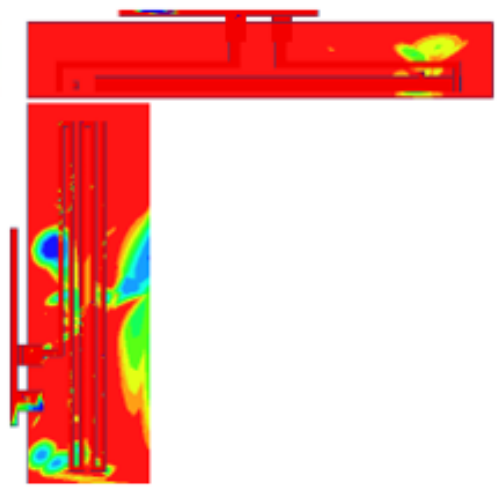

(f)

Figure 5 
Current distribution of the two antennas at different tuning frequency (a) $22 \mathrm{GHz}$, (b) $28 \mathrm{GHz}$, (b) $30 \mathrm{GHz}$, (d) $34 \mathrm{GHz}$ and (c) $44 \mathrm{GHz}$.

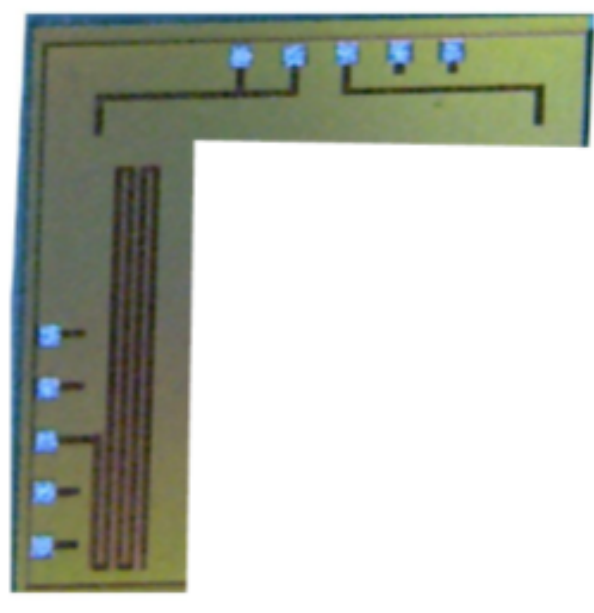

(a)

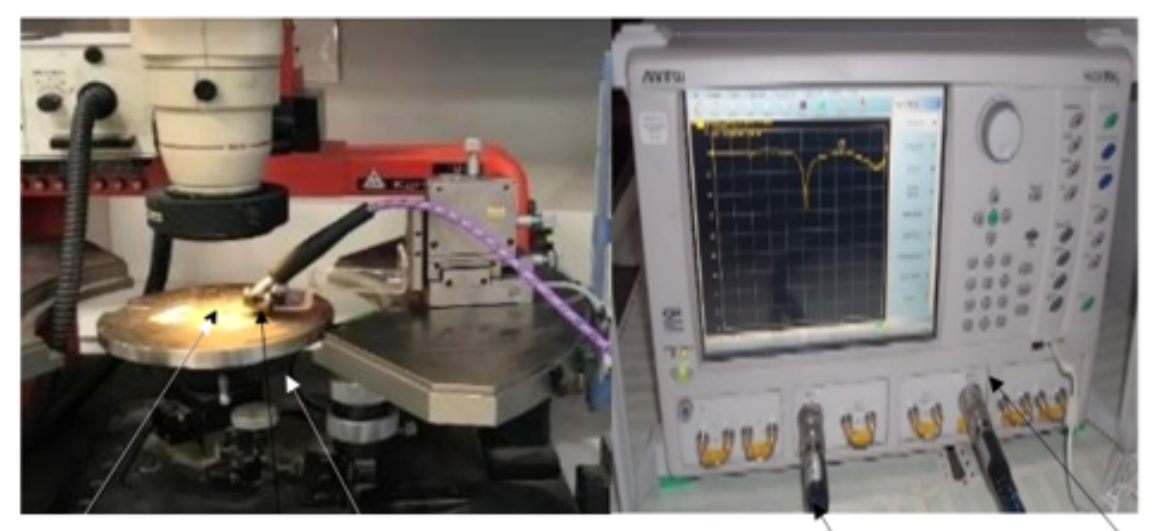

(b)

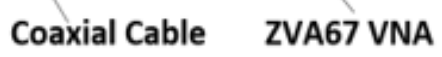

Antennas Chip GSG PicoProbe

\section{Figure 6}

(a) Photo of the fabricated antennas and (b) The reflection coefficient measurement setup.

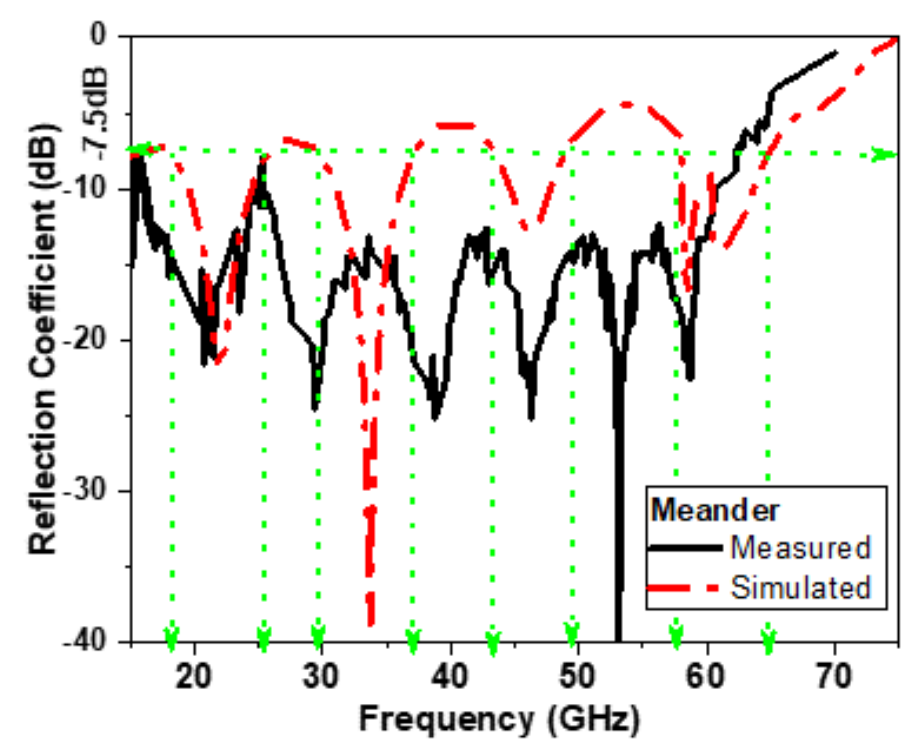

(a)

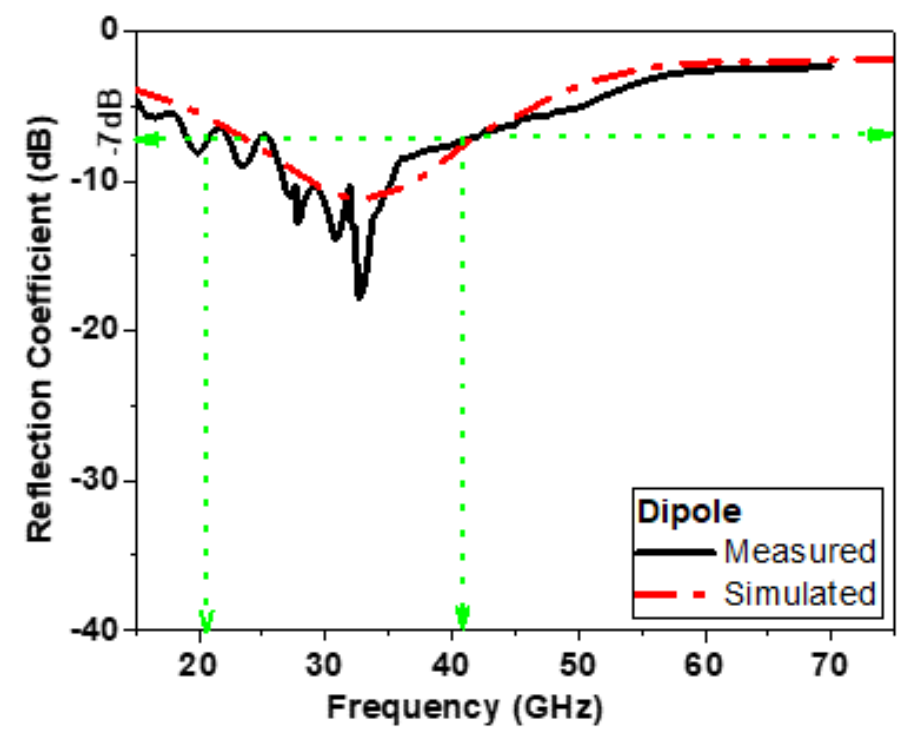

(b)

Figure 7

Comparison of the proposed antennas measured and simulated of |S11| (a) DBMA and (b) WBDA antenna. 


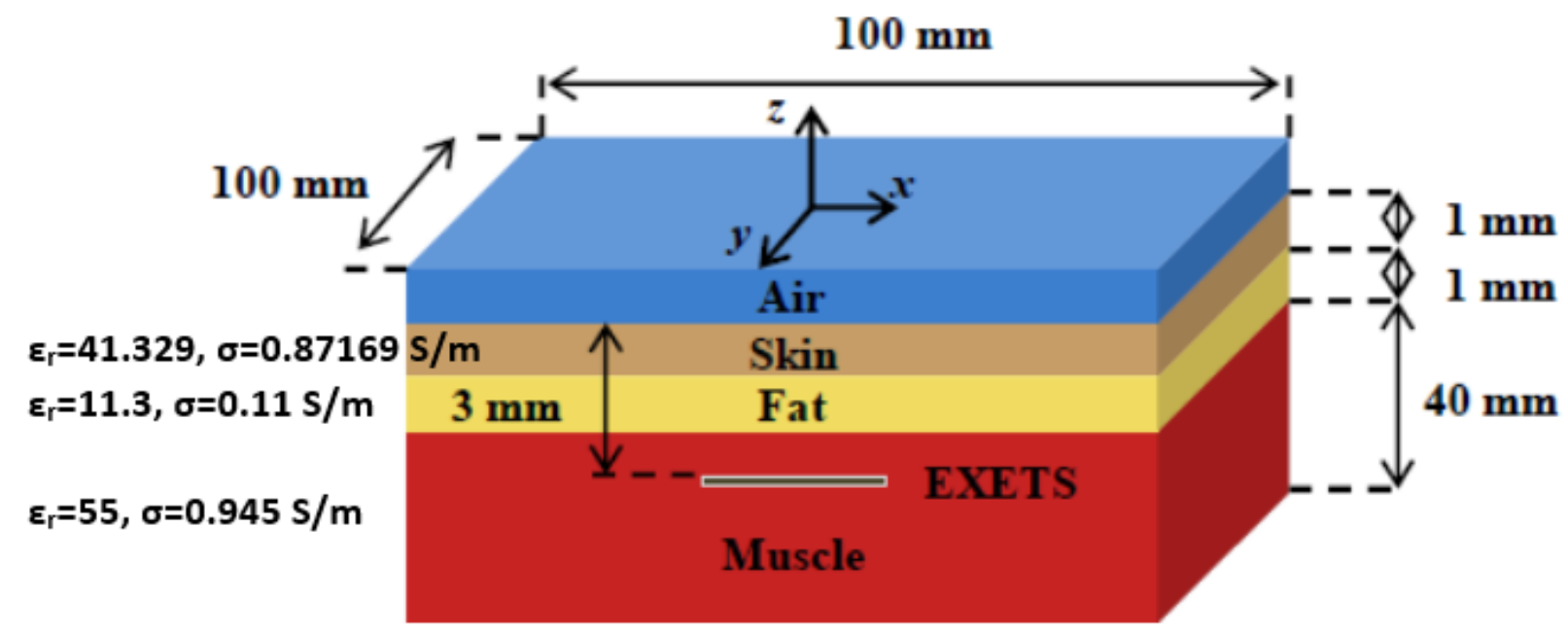

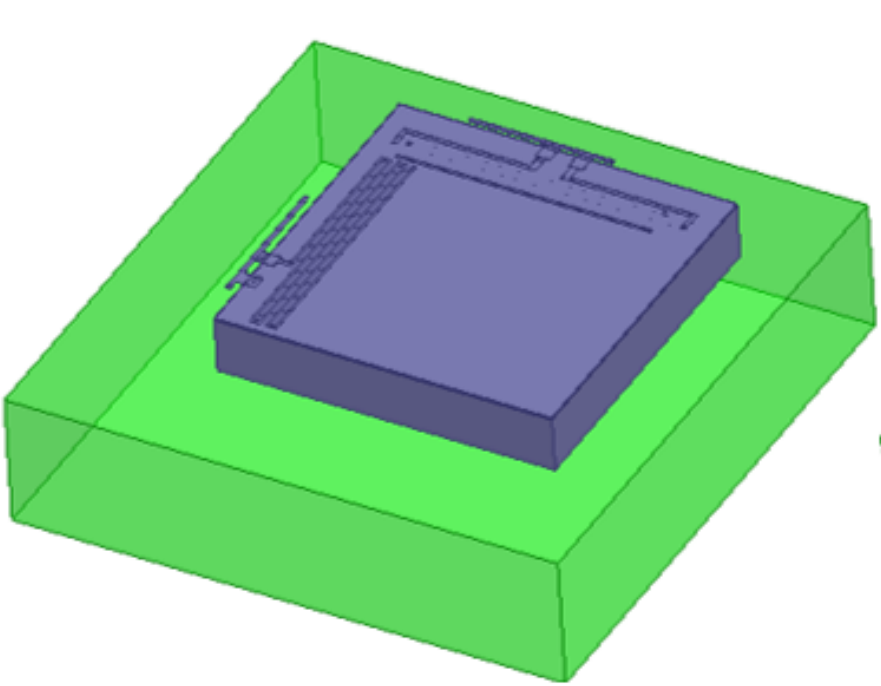

(b)

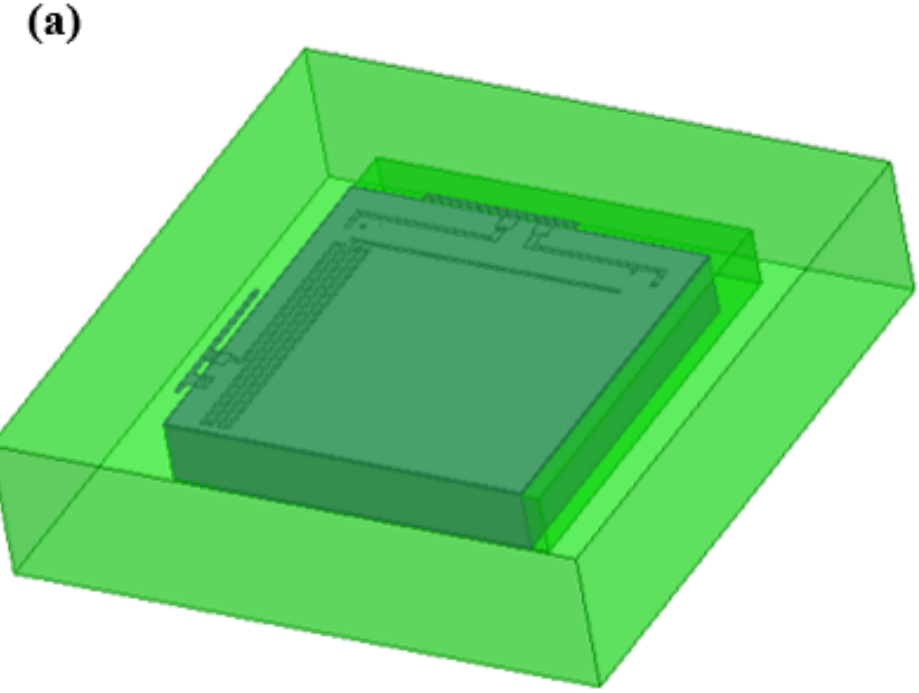

(c)

Figure 8

(a) Simulation model side view, proposed antennas system (b) outside the human phantom and (c) inside the human phantom. 


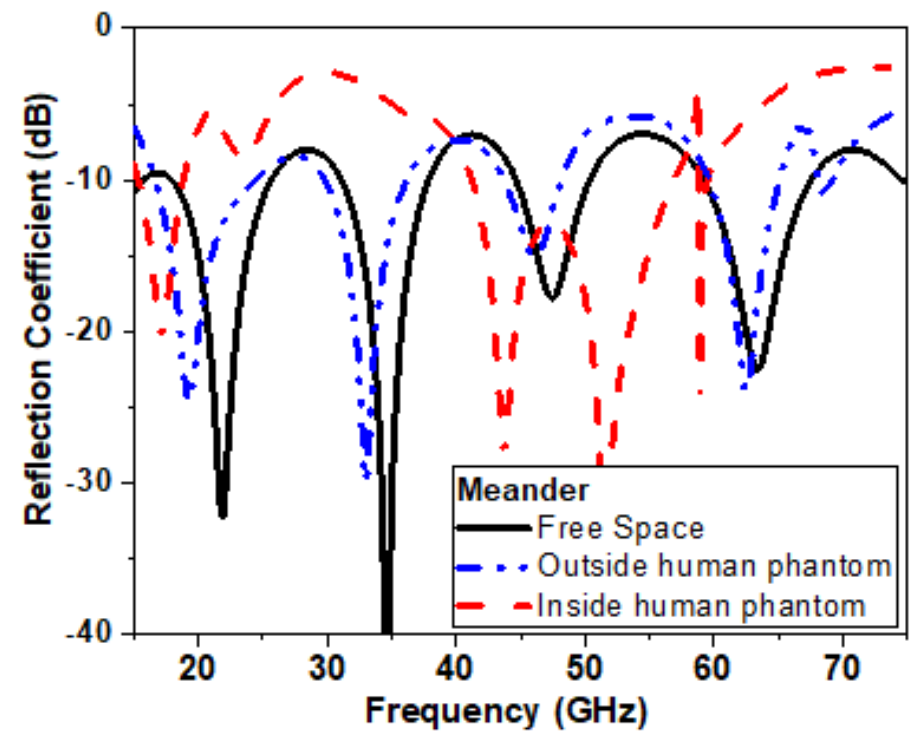

(a)

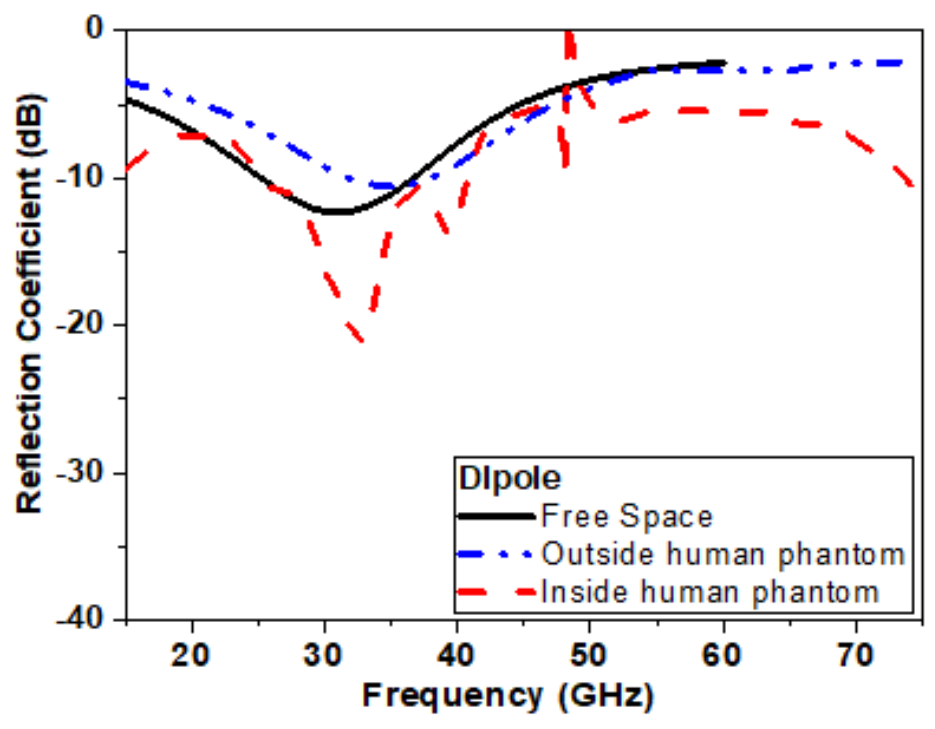

(b)

Figure 9

Reflection coefficient versus frequency (a) of the meander antenna and (b) of the dipole antenna. 